\title{
ENTREVISTA
}

\section{Esoterismo, Modernidade e Secularização: a Gnose de Samael Aun Weor}

El investigador Marcelo Leandro de Campos ha defendido una Tesis de Maestría en Ciencias de la Religión, cuyo título es "Esoterismo, Modernidade e Secularização: a Gnose de Samael Aun Weor" en la Pontificia Universidad Católica de Campinas, Brasil, el 3 de diciembre de 2015. Marcelo nació en 1970 en São Paulo, Brasil.

El autor nos ha concedido la siguiente entrevista.

¿Cuáles fueron los motivos que le llevó a enfocar su investigación hacia el Esoterismo?

Eu decidi cursar a graduação de História já próximo da casa dos 40 anos. Não é incomum que um historiador volte seu olhar para o passado em busca de temas que agitaram sua mocidade; jovens comunistas como Hobsbawn e Perry Anderson vão se converter, por exemplo, em intérpretes do mundo contemporâneo a partir de releituras bastante originais do marxismo. Movido por intensas inquietudes espirituais, eu militei ativamente, durante minha juventude, em escolas esotéricas; durante duas décadas em instituições neognósticas, atuando como instrutor, palestrante e dirigente; em seguida, por um breve período, como estudante na Fraternidade Rosacruz Antiqua, onde tive o privilégio de conhecer o fráter e grande mestre rosacruz Paulo Carlos de Paula. Mais tarde minhas buscas espirituais se alargaram e incluiram uma miriáde de grupos espiritualistas, da umbanda ao uso de ayahuasca. É muito recente o interesse acadêmico pelo esoterismo; a historiadora inglesa Frances Yates, no final da década de 1960, com seu magnífico trabalho sobre a influencia do hermetismo na constituição do humanismo renascentistas, é praticamente a precursora de uma historiografía sobre o tema. É natural, portanto, que sendo conhecedor de umA grande quantidade de fontes documentais até agora ignoradas pelo trabalho historiográfico, que preferisse concentrar meus esforços sobre elas. O sucesso de um primeiro trabalho sobre a história das correntes gnósticas contemporâneas acabou abrindo as portas para um mestrado no campo de Ciências da Religião, o que me permitiu aprofundar a pesquisa inicial. A história do esoterismo na América Latina é, literalmente, um terreno virgem que aguarda desbravadores.

¿Cuáles fueron las fuentes que ha utilizado?

Meu trabalho se concentrou sobre o conjunto da obra do esoterista colombiano Samael Aun Weor (1917-1977), especialmente seus primeiros livros, escritos na década de 1950. 
Samael, após um longo aprendizado na sociedade Teosófica, filiou-se à Fraternidade Rosacruz Antiqua; no final da década de 1940 rompeu com os rosacruzes e veio a constituir sua própria escola esotérica, o Movimento Gnóstico Cristão Universal; sua doutrina, centrada em exercícios de magia sexual, causou forte escândalo e o obrigaram a se mudar para o México, de onde sua doutrina se espalhou rapidamente por todo continente, atingindo a Europa a partir do final da década de 1970. Além de suas obras há ainda a Revista Rosacruz de Oro, publicação da Fraternidade Rosacruz Antiqua na Colômbia, desde a década de 1930, e a correspondência de Samael com seu discípulo Julio Medina, coordenador do Summum Supremum Sanctuarium, a sede gnóstica da Colômbia nas décadas de 1950 a 1970. Esse material foi cotejado com uma extensa produção memorialista que inicia com o próprio Samael, que deixou um relato autobiográfico num livro intitulado As Três Montanhas, seguido por uma série de relatos deixados por seus principais discípulos e familiares.

¿Cuáles fueron las principales dificultades con las que se ha encontrado? ¿Cómo las ha superado?

A maior dificuldade, seguramente, foi o acesso às fontes; as intituições gnósticas, salvo algumas exceções excepcionais, são bastante fechadas e pouco receptivas a receber pesquisadores académicos; essa dificuldade foi contornada graças à internet: um site intitulado gnosis2002.com, dirigido por Francisco Caparroz, permitiu um acesso à raríssima primeira versão do livro O Matrimônio Perfeito, primeiro livro escrito por Samael, em 1950. Parte da correspondência de Samael foi disponibilizada pelo site da Igreja Gnóstica, e algumas cartas foram publicadas por um site que faz oposição às instituições gnósticas, chamado La Gnosis Develada. A segunda dificuldade foi definir um aporte metodológico e conceitual para analizar as fontes; um pedregoso caminho foi percorrido até nos definirmos por uma abordagem histórico-cultural centrada em torno dos conceitos de imaginário e representação social; tive aquí a inestimável contribuição de minha orientadora, professora Ana Rosa Cloclet, e do professor Juan Bubello, diretor do CEEO-UNASUR. Finalmente, demandou um esforço tremendo reunir os trabalhos acadêmicos que se debruçam sobre a figura de Samael Aun Weor, com o propósito de apresentar um quadro geral dos estudos sobre a gnose samaeliana. Merecem destaque, aqui, a obra do antropólogo espanhol José Alvaro Lopez Bellas e do sociólogo italiano PierLuigi Zoccatelli, membro do CESNUR (Centro Estudi sulle Nuove Religioni), autor de um estudo sobre a influência do esoterista armênio P. Gurdjieff sobre a obra de Samael que constituiu o ponto de partida de nossa tese sobre o tema. Tive nesse esforço a inestimável colaboração do professor Franz Winter, da Universidade de Viena, autor de um interessante trabalho sobre as reapropriações do primitivo gnosticismo no esoterismo contemporâneo. 
¿Cuáles fueron las principales problemáticas históricas que su trabajo ha resuelto?

A obra de Samael e suas instituições constituem um tema interessante por estar situado em duas "fronteiras" espaço-temporais: a transição do tradicional ocultismo europeu do século XIX para o multifacetado universo de espiritualidades da assim chamada Nova Era dos anos de 1960, por um lado, e a ascensão da América Latina à condição de importante centro doutrinário e institucional no cenário esotérico mundial, com figuras como Carlos Castaneda, Paulo Coelho e tantos outros. Minha análise sobre a obra de Samael busca fundamentar uma tese que eu chamo de transição doutrinária, onde estou dialogando diretamente com as ideias de Pierluigi Zoccatelli; o sociólogo italiano acredita que Samael cria sua doutrina gnóstica, em 1950, já sob a influência da ideia de "psicologia esotérica" do esoterista russo P. Gurdjieff; eu acredito que meu trabalho demonstra que a doutrina do Quarto Caminho, como são conhecidas as ideias de Gurdjieff, somente aparecem na obra samaeliana no final da década de 1950; o gnosticismo samaeliano, em seu inicio, está fortemente ligado ao ritualismo esotérico da Fraternidade Rosacruz Antiqua colombiana, da qual participam o próprio Samael e muitos de seus primeiros discípulos. Essa psicologização da doutrina gnóstica, que se acentua na década de 1970, não teve aceitação unânime entre o discipulado de Samael, e constitui um dos agentes estruturais da fragmentação que as instituições gnósticas experimentam após a morte do seu líder: alguns grupos, como a Igreja Gnóstica de Júlio Medina, vão voltar ao modelo doutrinário dos primeiros anos, enquanto a Nova Ordem de Joaquim Amortegui vai radicalizar o processo de psicologização da doutrina: o ritualismo mágico é completamente substituído por um conjunto de práticas psicológicas que visam estimular o desenvolvimento da consciência.

Outra contribuição foi no sentido de analisar o gnosticismo samaeliano à luz do conceito de secularização do esoterismo, proposta pelo historiador holandês Wouter Hanegraaff, diretor do centro de estudos sobre o esoterismo da Universidade de Amsterdam. Hanegraaff condena a classificação das correntes esotéricas como antimodernas, mostrando como suas doutrinas e práticas operam uma profunda apropriação de ideias iluministas e científicas, a partir do século XIX, e como importantes instituições esotéricas contemporâneas, como a Sociedade Teosófica, atuam como importantes agentes da secularização das sociedades em que estão presentes. Essa análise é particularmente reveladora para meu objeto específico de estudos: a gnose samaeliana integra um grupo muito distinto de doutrinas esotéricas que se estruturam em torno de práticas mágicas de caráter sexual; essa Magia Sexual constitui uma releitura ocidental do tantrismo hindu, onde se destacam autores como o mago inglês Aleister Crowley e o rosacruz alemão Arnold Krum-Heller. Estas práticas, que são vistas com desconfiança dentro do próprio milieu esotérico e que constituiriam seu lado mais antimoderno, na verdade estão perfeitamente integradas às concepções científicas do século XIX em relação ao corpo humano e suas dinâmicas de regeneração e degeneração, então fortemente influenciadas por 
noções do evolucionismo darwinistas então em voga.

¿Por favor, podría resumir la esencia de su Tesis en dos líneas?

Essencialmente, meu trabalho se debruça sobre a história de uma escola esotérica colombiana, o Movimento Gnóstico Cristão Universal, e a análise do nascimento e desenvolvimento de sua doutrina.

¿Cuáles fueron las lecciones, a todos los niveles, personal y profesional, que usted ha deducido de su experiencia investigativa?

Conduzir uma investigação acadêmica constitui, acima de tudo, uma grande e transformadora experiência de vida; todo o processo de aprendizado sobre teoria e metodologia, e sua aplicação prática, são muito ricos e ao mesmo tempo constituem lições de humildade: os historiadores de hoje têm plena consciência do caráter provisório do resultado de suas pesquisas; elas brevemente serão superadas e complementadas por novas contribuições, por novas descobertas; essa é, ao mesmo tempo, a grande magia dessa lida: é um trabalho permanente de construção do conhecimento. Aprendi muito com os historiadores do nascente campo de História do Esoterismo Ocidental, como Wouter Hanegraaff e Nicholas Goodrick-Clarke, ou os autores mais recentes, como Marco Pasi e Henrik Bogdan; a Europa tem revelado sucessivas levas de excelentes pesquisadores sobre as correntes esotéricas.

Como parte da pesquisa, tive a oportunidade de participar de uma série de eventos acadêmicos nas áreas de História e Ciências da Religião. Um deles, particularmente marcante, ocorreu na Universidade Lusófona de Lisboa; seu mestrado de Ciências da Religião possui diversas disciplinas voltadas ao estudo do gnosticismo primitivo e das correntes esotéricas contemporâneas. Esses eventos me convenceram da importância de se fortalecer o paradigma de que devemos estudar religião e espiritualidades, enquanto chaves culturais para se compreender uma determinada sociedade, a partir de um enfoque rigorosamente interdisciplinar; apenas uma estreita colaboração entre historiadores, antropólogos, sociólogos e psicólogos pode permitir avanços na compreensão de um objeto tão específico e polimórfico como a religiosidade humana.

¿Ahora, cuáles son sus proyectos profesionales?

O grande objetivo é prosseguir as pesquisas através de um doutorado na área de História; a primeira ideia é desenvolver um projeto de pesquisa visando o programa de pósgraduação em história da Universidade de Campinas (Unicamp), que oferece uma interessante linha de pesquisa sobre cultura e religião. O primeiro esboço do projeto se 
debruça sobre a presença do esoterismo no Brasil na virada entre os século XIX e XX, onde estão fervilhando grupos espíritas, teosóficos e propostas espiritualistas como o Círculo Esotérico da Comunhão do Pensamento, fundado em 1907 em São Paulo. Também existe a intenção de me vincular a grupos de pesquisa acadêmica sobre esoterismo e de estabelecer vínculos mais estreitos com outros pesquisadores e com os projetos do Centro de Estudos do Esoterismo Ocidental da UNASUR (CEEO-UNASUR), dirigido pelo professor Juan Pablo Bubello.

¿Quisiera destacar algún aspecto que no se ha contemplado y que usted consideraría digno de reseñar?

Gostaria de destacar a importância de trabalhos acadêmicos sobre as doutrinas esotéricas e suas escolas na América Latina. Como têm revelado as pesquisas de autores como Devés Valdés e Melgar Rao, o esoterismo e suas instituições tiveram uma importante influência política, cultural e social, ainda pouco estudada. A pesquisadora espanhola Marta Elena Casaus Arzú, por exemplo, em sensacional artigo publicado pela REHMLAC, destaca a importância que a teosofia exerceu sobre a intelectualidade centroamericano nas décadas de 1920 e 1930. O esforço destes pioneiros, e de órgãos como a própria REHMLAC e o CEEO-UNASUR é significativo no esforço de superar os preconceitos que ainda se observam nos meios acadêmicos sobre estes temas. Essa área também é carente de iniciativas voltadas à preservação e divulgação de seus acervos documentais; nesse sentido gostaria de divulgar e apoiar o maravilhoso trabalho conduzido pela equipe do site Sanctasanctorum.org no sentido de digitalizar e tornar acessíveis documentos e publicações de lojas teosóficas, rosacruzes e maçônicas na América Latina nos séculos XIX e XX, constituindo assim um importante patrimônio que pode servir como ponto de partida de novas pesquisas.

Esta entrevista se efectúo de forma telemática el 4 de febrero de 2016.

Autores de la entrevista: Ricardo Martínez Esquivel e Yván Pozuelo Andrés, Director y Editor de REHMLAC+.

DOI: http://dx.doi.org/10.15517/rehmlac.v8i1.24282 